\title{
The Energy Cooperation and Knowledge Technology Transfer between China and Saudi Arabia
}

\author{
Dr. Saleh L. Alghamdi, Muhammed Y. Alzaid \\ University of Jeddah, Saudi Arabia \\ University of International Business \& Economics UIBE, China
}

\begin{abstract}
Saudi Arabia is an oil-based economy with the biggest proven crude oil reserves in the world at 266.7 billion barrels, New oil and gas fields has been discovered in the past three years, representing more than $57 \%$ of the (GCC) Gulf Commission Council Countries reserves, nearly 29\% of the OPEC and almost $20 \%$ of the world total reserves. It ranks as the largest and biggest producer as well as exporter of petroleum in the world and plays a leading major role in the OPEC, producing almost $30 \%$ of the total OPEC oil production. Oil sector represented $90 \%$ of total export earnings, $80 \%$ of government's revenue and almost 45\% of its GDP. About $40 \%$ of GDP comes from the private sector. The average OPEC basket oil price stood at US\$34.39 per barrel in the 1st four months of 2016 compared to $\$ 91.48$ a barrel in the same period of 2008, recording a huge annual decrease in the government revenue.

Saudi Arabia aggressively encourages foreign investment, mainly if the projects have a strong and essential developmental effect on the country's economy and encourage industrialization and technology transfer to the Kingdom. Saudi law requires that technology transfer must occur in any foreign invested projects to benefit the country industrial development. Moreover, foreign investors can invest and own their assets in their own name. However, the petroleum and mineral extraction industries are owned and controlled by the government and are usually closed to foreign investment except big organizations in this industry that can guarantee access to this industry thru Joint venture with local companies
\end{abstract}

Keywords: Energy, Knowledge Transfer, Technology Transfer, Saudi-China Joint-Venture

\section{KNOWLEDGE \& TECHNOLOGY TRANSFER DEFINITION}

Knowledge and technology is seen as an important intangible corporate intellectual capital, which is different from the current machinery, land, equipment, cash and other tangible assets in the financial statements. Intellectual capital includes human capital, structural capital and customer capital ${ }^{1}$. These are intangible, which cannot be seen from the financial statements, but it determines the company's potential and future competitive advantage ${ }^{2}$ ). UNIDO believes that technology is the sum of knowledge, experience and skills for enterprises aiming at manufacturing one or more products ${ }^{3}$. Different understandings for knowledge are often combined with the classification of knowledge. Some conclusions can be drawn from the current literature that the standard classifications of knowledge for scholars include the following aspects: the role of knowledge and technology, the degree of difficulty to obtain and transfer knowledge, details of the attached carrier. Many scholars may also refer to two or more dimensions when compartmentalizing knowledge and technology. For instance, the classification of knowledge and technology of Hedlund ${ }^{4}$ is a combination of two dimensions: the difficulty degree of acquisition or transfer of knowledge as well as the attached carrier of knowledge 5 .

\section{ENERGY COOPERATION}

The energy cooperation between China and Saudi Arabia has a solid foundation for the development. In the distant ancient times, China has had contacts with Arabia that located at the intersection of three continents of Asia, Africa and Europe. There are too many historical witnesses since second century BEC. Such as the Silk Road and the Spice Route. At the beginning of twenty-first Century, the successful launch of cooperation forum between China and Saudi Arabia promotes energy cooperation forward. Mutual benefit and win-win attitude results in a strong vitality of the energy cooperation. In order to meet the needs of today's development in the international situation and strategic cooperation, 
the current energy cooperation extends to the new energy field and promote the economic and trade cooperation to investment, science, technology, infrastructure, finance and other areas. China and Saudi Arabia confirm the partnership of energy development in a full range.

Chinese Premier declared new energy policy in the World Future Energy Summit held in Abu Dhabi in January 2012.He proposed to put energy efficiency in the first place, develop new and renewable energy, promote the revolution in energy science and technology and ensure the safety of energy. All of this caused people's response and resonance, including a number of state officials and scholars in Arabia ${ }^{6}$. Saudi Arabia's foreign ministry official said: "Premier Wen attended the summit, which fully shows the Chinese government's emphasis on sustainable development and renewable energy. He called on us to carry out more extensive cooperation in the field of renewable energy, which we are very welcome".

In the keynote speech at the opening ceremony of the Sixth Ministerial Conference in June 5, 2014, President Xi stressed that "Belt and Road Initiative is a win-win way. Because of the Silk Road plan, Saudi Arabia and China, that starts to communicate. We are natural partners in building 'The Belt and Road'. The two sides should stick to the principles of joint consultation, $\mathrm{CO}$ creation, and common enjoyment in order to form a benefit community and a fate community together". Saudi Arabia also endorsed President Xi's views on strengthening the forum construction and the development of bilateral strategic cooperation, supported to build China's Belt and Road Initiative ${ }^{7}$

Energy issues related to the core interests of China's pursuit of peaceful development. Over the years, there is a prominent contradiction in the poor structure of energy resources ${ }^{8}$. China's energy production and development lag behind the growth of energy demands. Supply and demand gap is mainly concentrated in the energy varieties of oil and gas that are relatively clean and efficient. Import relying degree of crude oil has increased from 1.2\% in 1996 to 58.6\% in 2013 and import relying degree of natural gas from $2 \%$ in 2008 rose to $30 \%$ in 2013.China will not only continue to maintain the identity of the world's largest oil importing country, and may become the world's largest importer of natural gas from 2015 to 2020. By 2020, China's crude oil and natural gas imports will be as high as 4.5 tons and 1500 1600 billion cubic meters. At present, China is in the rapid development of industrialization and urbanization, and the social and economic development is more dependent on the energy than the developed countries. Mitigation of energy bottlenecks directly connected to the social and economic development, improvement of people's life, the climate and environment changes and even national security interests. Arabia has always been China's largest source of oil import. Its share has been maintained at 50\% from 2002 to $2013^{9}$. Facts have proved that strategic cooperation mechanism and knowledge transfer mechanism is effective ${ }^{10}$.

\section{Findings \& CONCLUSION}

Cooperation Forum has played a huge role in linking between past and future, planning guidance, communication for energy cooperation between China and Saudi. Energy cooperation between China and Saudi Arabia is mutually dependent through bilateral economic relations. China needs a stable oil supply from Saudi Arabia; Saudi Arabia needs a stable oil export market and a US dollar investment site. So, this interdependence has laid a solid foundation for the development of China's energy cooperation with Saudi Arabia. Further advancement and extension of the energy strategic cooperation reflect the following aspects ${ }^{11}$ :

- Energy cooperation is a part of the wide-ranging cooperation between China and Saudi Arabia. Both sides should take into account the interests and understand the connotation of energy security with the perspective of dialectics, connection and development. We can't only put the understanding of energy security narrowly confined to the security perspective of energy consuming countries, but also consider the energy safety and practical interests in energy producer, exporter and transit country. Only in this way can we continue to promote the healthy and sustainable energy strategic cooperation continues to deepen.

- For China, we should correctly handle the relationships between imports diversification of oil and gas source and main channels. At the same times we should also see the challenges facing the energy cooperation, see a series of reality and potential challenges and obstacles in China and Saudi Arabia's oil and gas trade, exploration and development cooperation, etc. Long-term and complex of Middle East unrest will also enable energy cooperation further faced a series of unstable and uncertain impact and challenge. 
- In order to promote and improve the energy cooperation, the two sides need to strengthen communication and coordination, understand and cooperate in the new situation. We should not only deal with a series of related problems of oil and gas import and export trade, including the trade balance problem with other merchandise, oil pricing in the Asian premium, but also effectively promote the cooperation between two sides in the field of the exploration, development, transportation, refining, marketing and other aspects in mutual investment, business cooperation projects and labor contract. At the same time, we can strengthen the cooperation of renewable energy and jointly cope with climate change, expand the interests of the intersection, so that both sides have the benefit and achieve a win-win situation.

\section{REFERENCES}

[1] Petrash,G. 1996, Doo's Journal to a knowledge value management culture. European Management Journal. 14(4):365,373.

[2] Edvinson. L.and Malone, M.S.1997, Intellectual capital: Realizing your company's true value by finding its hidden brainpower. New York: Harper Business.

[3] Darr.E.D, and Kurtzbery, T.R. 2000, An investigation of partner similarity dimensions on knowledge transfer. Organizational Behavior and Human Decision Processes, 82 (1):28 - 44.

[4] Hedlund,G. 1994, A mode of knowledge management and the $N$-form corporation. Strategic Management Journal 15(52):73 - 90.

[5] Pan Guang, Yu Jianhua: "from the Silk Road to Asia Europe Meeting: Asia Europe relations two thousand years", Beijing: Central Party School of the Communist Party of China Press, 2004, $4 \sim 8$.

[6] Wen: the deepening comprehensive cooperation to achieve common development -- the speech of the Sino Saudi cooperation forum opening theme in the fourth ministerial meeting ", May 13 2010 ,

[7] XI: "carry forward the spirit of the Silk Road to deepen the cooperation between China and Saudi Arabia, the speech of the Sino Saudi cooperation forum opening theme in the Sixth ministerial meeting", "people's Daily" June 6. 2014.

[8] BP Statistical Review of World Energy, London, June 2014, p.10.

[9] TianChunrong: "the status of China's oil imports and exports in 2013", "the international oil economy" 2014, 3

[10] Zhang Kang, Lu Xuemei: "analysis and related issues about Chinese oil import and export", the " the international oil economy" 2012.8

[11] Yu Jianhua. "The world's energy politics and Chinese international energy cooperation", Changchun: Changchun Press, 2011, 3252

Citation: Dr. Saleh L., Alghamdi, and Alzaid Muhammed Y. "The Energy Cooperation and Knowledge Technology Transfer Between China And Saudi Arabia." International Journal of Managerial Studies and Research (IJMSR), vol 5, no. 8, 2017, pp. 1-3. doi:http://dx.doi.org/10.20431/2349-0349.0508003.

Copyright: () 2017 Authors. This is an open-access article distributed under the terms of the Creative Commons Attribution License, which permits unrestricted use, distribution, and reproduction in any medium, provided the original author and source are credited. 